\title{
Gangrenous Cholecystitis: A Grim Complication of Acute Cholecystitis
}

Liaqat A. Khan", Faisal I. Zaidan, Ali H. Masmali, Yahya M. Daghriri, Laila E. Asiri, Salwa A. Dohal, Taher A. Sumaili, Hussam M. Halawi

General Directorate of Health Jazan, Kingdom of Saudi Arabia

\begin{tabular}{|c|c|}
\hline Driginal Research Article & $\begin{array}{l}\text { Abstract: Gangrenous cholecystitis (GC) or necrotizing cholecystitis, a grim } \\
\text { complication of acute cholecystitis with high morbidity and mortality, commonly seen } \\
\text { in old age and patients with concurrent co-morbidities like diabetes. The patients may } \\
\text { present with or without signs of acute cholecystitis. Early identification and case- } \\
\text { specific intervention are vital to avoid an unwanted outcome. Physicians working as } \\
\text { first-level responders such as emergency or primary care should be vigilant to diagnose } \\
\text { and to plan a case-based intervention to prevent the potentially worst outcome. } \\
\text { Keywords: Cholecystitis, Gangrenous, Gallbladder, Gall Stones.. }\end{array}$ \\
\hline$\underset{10.36347 / \text { sasjm }}{\text { D }}$ & $\begin{array}{l}\text { INTRODUCTION } \\
\text { Gangrenous or acute necrotizing cholecystitis is an uncommon but dreadful } \\
\text { complication of acute cholecystitis. The characteristics feature is gas in the gallbladder } \\
\text { (GB) lumen or intramural, which in turn is due to gas-forming enteric bacteria resulting } \\
\text { in gangrene and even perforation of the GB. The underlying pathology is not clear but } \\
\text { thought to be ischemia of the GB wall followed by proliferation of enteric bacteria } \\
\text { resulting in gas formation [1, 2]. Males are affected more than females. Other } \\
\text { predisposing conditions include older age, diabetes mellitus, low immune system, gall } \\
\text { stones, and recurrent cholecystitis [2-4]. Herein we report an aged patient with a known } \\
\text { history of diabetes, hypertension, and hyperlipidemia with a history of vomiting, } \\
\text { intolerance to food, fever, and upper abdominal pain. A detailed evaluation of the } \\
\text { patient, coupled with radiological findings, revealed acute necrotizing cholecystitis and } \\
\text { was managed surgically. }\end{array}$ \\
\hline
\end{tabular}

\section{Case Presentation}

A 67years old male, a known patient of Type 2 diabetes mellitus, hypertension, and hyperlipidemia for the last 15 years presented to the emergency department (ED) with a two-day history of nausea, non-bilious vomiting, two episodes of loose bowel, fever, and mild upper abdominal pain. The patient avoids meals due to an increase in pain intensity and vomiting.

The patient's vitals in the ED were; Temp $98.5 \mathrm{~F}^{0}$, pulse $87 / \mathrm{min}$, BP $188 / 81$, R/R 19/min. Oxygen saturation was $98 \%$ on room air. Laboratory workup shows; blood glucose $498 \mathrm{mg} / \mathrm{dL}$, urine ketones $-\mathrm{ve}, \mathrm{Hb}$ $9.7 \mathrm{~g} / \mathrm{dL}$, platelets $546 \times 10^{3} / \mu \mathrm{L}$, white blood count (WBC) $19.6 \mathrm{k} / \mathrm{uL}$, serum sodium $\left(\mathrm{Na}^{+}\right) 134 \mathrm{mmol} / \mathrm{L}$, serum potassium $\left(\mathrm{K}^{+}\right)$, creatinine $61.3 \mathrm{mg} / \mathrm{dL}$, alkaline phosphatase $189 \mathrm{U} / \mathrm{L}$, TBil $3.5 \mathrm{mg} / \mathrm{dL}$, and DBil 2.4 $\mathrm{mg} / \mathrm{dL}$. Physical evaluation of the patient revealed normal systemic findings except a tender upper abdomen more at the right quadrant with negative Murphy's sign.

The patient was admitted to the surgical unit under both surgical and medical care for her high blood glucose levels. Abdominal sonography performed, showing a dilated gallbladder (GB) with a thickness of $14 \mathrm{~mm}$, with sludge, and two big and more small stones suggestive of acute cholecystitis. Abdominal computed tomography scan showed gas in the lumen of the gallbladder, multiple gall stones, pericholecystic fluid, and irregular balder wall suggesting impending wall rupture (Fig-1). The patient started on AmpicillinTazobactam and intravenous insulin.

The next day the patient has one episode of fever of $101 \mathrm{~F}^{0}$ with chills. Laparoscopic cholecystectomy planed for the patient. Intraoperative findings include dense adhesions with omentum over the gallbladder and a gangrenous GB. Due to severe adhesions and difficulty in dissection, an open cholecystectomy opted for removal of the gangrenous GB. The abdomen was closed in layers with a drain in the gallbladder bed. Postoperatively the patient did well drain removed on $2^{\text {nd }}$ post-op day, and the patient was discharged on $6^{\text {th }}$ post-op day with a week later followup. The patient was doing well during her $1^{\text {st }}$ follow-up visit. 


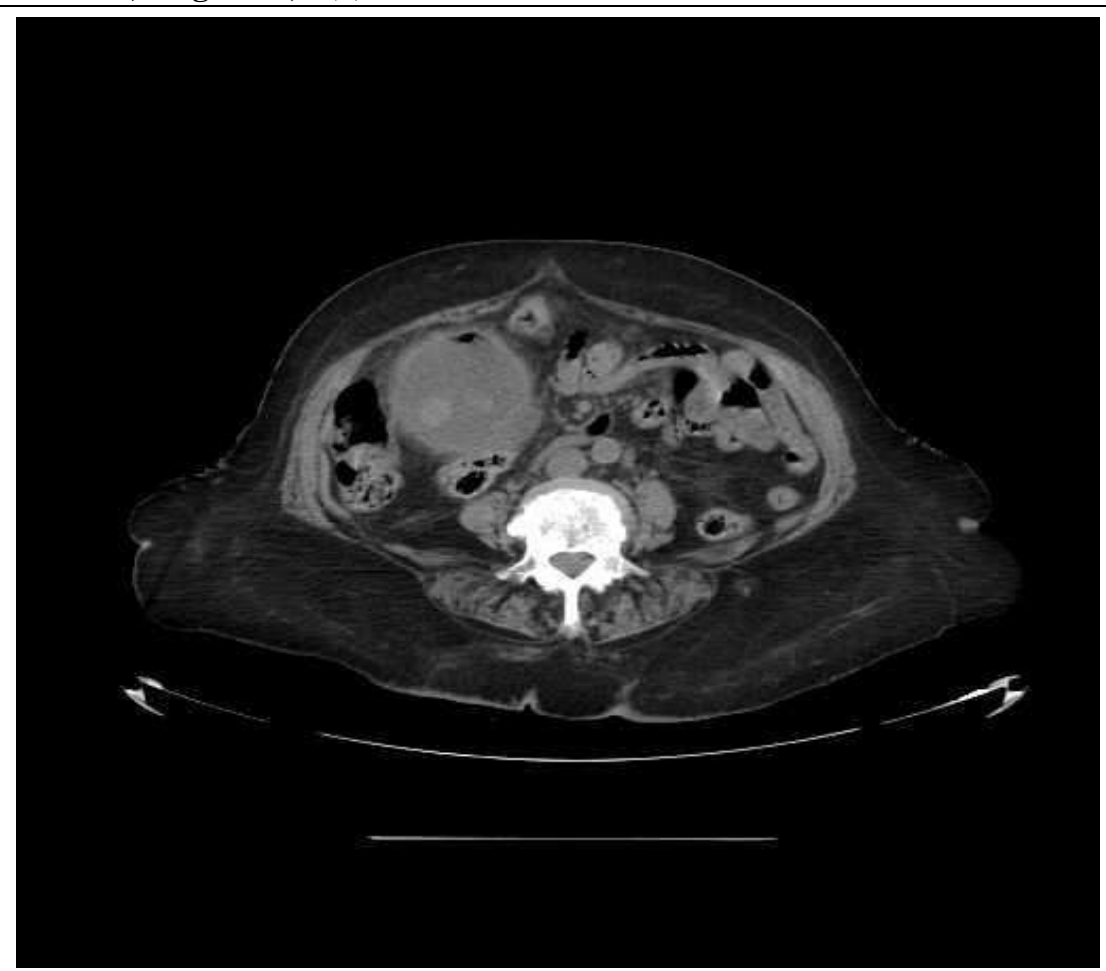

Fig-1: Non-contrast CT abdomen showing intraluminal gas and stones in the gallbladder

\section{DISCUSSION}

Gangrenous cholecystitis (GC), also called acute necrotizing cholecystitis, is un-usual but a grim complication of acute cholecystitis, commonly seen in older patients with underlying co-morbidities. The underlying pathophysiology is increased pressure of the GB wall due to growth of the gas-producing bacteria leading to vascular compromise and gangrene of the GB $[1,2,4]$. The commonly cultured micro-organisms include clostridium perfringens and Escherichia coli. Other micro-organisms include staphylococcus, streptococcus, proteus, klebsiella, and bacteroids fragilis [5]. The first case of gangrenous cholecystitis (GC), reported by Stolz [6] at autopsy. There are multiple case reports of gangrenous cholecystitis in the published literature.

Ultrasonography is the first line of imaging modality for suspected patients to confirm the diagnosis. In a situation where sonographic findings are inconclusive, computed tomography (CT) has high specificity to confirm the diagnosis of GC [2].

The gold standard of management includes surgical removal of the gallbladder without any delay through an open or laparoscopic procedure. Conservative treatment may have opted for stable and milder cases. However, open cholecystectomy has opted for older patients and those with co-morbid conditions [7]. Laparoscopic removal of the gallbladder may be an alternative to open with a success rate of $91 \%$ in uncomplicated patients [8]. Experienced surgeons preferably opt for laparoscopic cholecystectomy, and the latter may convert to an open procedure in case he/she feels so. However, laparoscopic removal has a better outcome with minimal hospital stay postoperatively.

\section{CONCLUSION}

Early identification of patients with gangrenous cholecystitis is imperative to avoid the unwanted outcome. Physicians working as first-level responders such as emergency or primary care should be aware of such grim complication of acute cholecystitis to diagnose patients with GC as to plan case-specific intervention to avoid the worst outcome.

\section{Ethical approval: Not applicable}

Consent: Written, informed consent, taken from the patient for publication of the data.

Conflict of Interest: The authors declare that they have no conflict of interest.

\section{REFERENCES}

1. Chiu HH, Chen CM, Mo LR. Emphysematous cholecystitis. Am J Surg. 2004;188: 325-6.

2. Bennett GL, Rusinek H, Lisi V, Israel GM, Krinsky GA, Slywotzky CM, Megibow A. CT findings in acute gangrenous cholecystitis. AJR Am J Roentgenol 2002; 178(2): 275-281.

3. Ogawa A, Shikata K, Uchida HA, Shinoura S, Yokomichi N, Ogawa D, Sato-Horiguchi C, Yagi T, Wada J, Makino H. Case of emphysematous cholecystitis in a patient with type 2 diabetes mellitus associated with schizophrenia. Journal of diabetes investigation. 2012 Dec;3(6):534-5. 
4. Chaudhry S, Hussain R, Rajasundaram R, Corless D. Gangrenous cholecystitis in an asymptomatic patient found during an elective laparoscopic cholecystectomy: a case report. Journal of medical case reports. 2011 Dec;5(1):1-3.

5. Sunnapwar A, Raut AA, Nagar AM, Katre R. Emphysematous cholecystitis: imaging findings in nine patients. Indian J Radiol Imaging. 2011; 21:142-146.
6. Stolz A. Ubergasbildung in derGollinweger. Arch Pathol Anat. 1901; 165:90-123.

7. Bingener J, Stefanidis D, Richards ML, Schwesinger WH, Sirinek KR: Early conversion for gangrenous cholecystitis: impact on outcome. Surg Endoscopy. 2005; 19(8):1139-1141.

8. Hunt DR, Chu FC. Gangrenous cholecystitis in the laparoscopic era. Australian NZ J Surg. 2000, $70(6): 428-430$ 